\title{
EFFECTIVE CONTROL OF PULMONARY VASCULAR RESISTANCE WITH INHALED NITRIC OXIDE AFTER CARDIAC OPERATION
}

David A. Fullerton, MD

Stephen D. Jones, MD

James Jaggers, MD

Fran Piedalue, RRT

Frederick L. Grover, MD

Robert C. McIntyre, Jr., MD
Increased pulmonary vascular resistance may greatly complicate the perioperative management of cardiac surgical patients. Inhaled nitric oxide may be a promising new therapy to selectively lower pulmonary vascular resistance. The purpose of this study was to examine the effects of inhaled nitric oxide on pulmonary and systemic hemodynamics in cardiac surgical patients. Twenty patients (age $57 \pm 6$ years) were studied in the operating room after weaning from cardiopulmonary bypass. Mean pulmonary artery pressure, pulmonary vascular resistance, systemic vascular resistance, and mean aortic pressure were determined at four points of data collection: before nitric oxide, with 20 ppm nitric oxide, with 40 ppm nitric oxide, and after nitric oxide. Statistical analysis was by analysis of variance; significance was accepted for $p<\mathbf{0 . 0 5}$. Inhaled nitric oxide produced selective pulmonary vasorelaxation. Pulmonary vascular resistance was lowered from $343 \pm 30$ before nitric oxide to $233 \pm 25$ dynes $\cdot \mathrm{sec}^{-1} \cdot \mathrm{cm}^{-5}$ with 20 ppm nitric oxide. Pulmonary vascular resistance was not further lowered by $40 \mathrm{ppm}$ nitric oxide $(p<0.05)$. Mean pulmonary arterial pressure was $29 \pm 1 \mathrm{~mm} \mathrm{Hg}$ before nitric oxide and was lowered to $22 \pm 1$ $\mathrm{mm} \mathrm{Hg}$ by $20 \mathrm{ppm}$ nitric oxide and $21 \pm 1 \mathrm{~mm} \mathrm{Hg}$ by $40 \mathrm{ppm}$ nitric oxide $(p<0.05)$. Both pulmonary vascular resistance and mean pulmonary arterial pressure returned to baseline after withdrawal of inhaled nitric oxide. Inhaled nitric oxide produced no changes in either systemic vascular resistance or mean aortic pressure. We conclude that nitric oxide may be used as an effective pulmonary vasodilator after cardiac operations. It may be particularly valuable for selectively lowering right ventricular afterload in patients with right ventricular dysfunction. (J THORAC CARDIOVASC SuRG 1996;111:753-63) ncreased pulmonary vascular resistance (PVR) may greatly complicate perioperative management of cardiac surgical patients. Because PVR is the primary clinical determinant of right ventricular afterload, increased PVR may result in right ventricular afterload mismatch, compromising cardiac

From the Department of Surgery, University of Colorado, Denver, Colo.

Supported by NIH grant R29HL49398.

Read at the Twenty-first Annual Meeting of The Westem Thoracic Surgical Association, Coeur d'Alene, Idaho, June 21-24, 1995.

Received for publication June 21, 1995; revisions requested Oct. 3, 1995; revisions received Oct. 11, 1995; accepted for publication Nov. 8, 1995.

Address for reprints: David A. Fullerton, MD, Cardiothoracic Surgery, University of Colorado Health Sciences Center, Box C-310, 4200 E. Ninth Ave., Denver, CO 80262.

Copyright (C) 1996 by Mosby-Year Book, Inc.

$0022-5223 / 96 \$ 5.00+0 \quad \mathbf{1 2 / 6 / 7 0 5 4 1}$ output (CO). Pharmacologic agents currently used as pulmonary vasodilators produce vasodilation of both the systemic and pulmonary circulations. Such nonselective vasodilation may be hazardous in patients with increased $\mathrm{PVR}^{1,2}$; significant hypotension may result if the degree of systemic vasodilation exceeds that of the pulmonary vasodilation.

When administered to patients with adult respiratory distress syndrome (ARDS), inhaled nitric oxide (NO) has been shown to improve oxygenation and to lower PVR. ${ }^{3,4}$ It has also been shown to lower PVR in pediatric cardiac surgical patients with pulmonary hypertension. ${ }^{5}$ We therefore hypothesized that NO would effectively vasodilate the pulmonary circulation without producing unwanted systemic vasodilation in adult cardiac surgical patients.

The purpose of this study was to examine the pulmonary and systemic hemodynamic effects of 


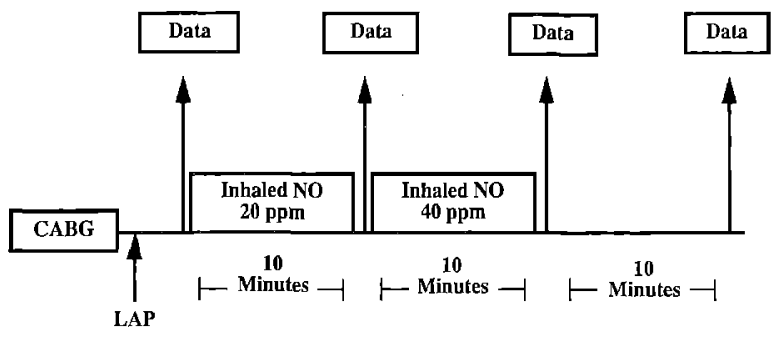

Fig. 1. Experimental protocol. After separation from cardiopulmonary bypass and administration of protamine, LAP monitoring catheter was placed. Baseline hemodynamic data were collected, and inhaled NO was then administered. Data were collected after 20 and $40 \mathrm{ppm}$ NO. Hemodynamic data were collected after withdrawal of NO. $C A B G$, Coronary artery bypass grafting; $L A P$, LAP monitoring catheter.

inhaled NO in adults after cardiac operations. $\mathrm{Pa}-$ tients undergoing aorta-coronary bypass operations were studied in the operating room while under general anesthesia. Inhaled $\mathrm{NO}$ was administered in two concentrations, 20 and $40 \mathrm{ppm}$. The results of this study demonstrate that inhaled NO effectively reduced PVR and mean pulmonary arterial pressure (MPAP) without affecting systemic vascular resistance (SVR) or systemic arterial pressure (SAP). These data suggest that inhaled NO may be used clinically in adult cardiac surgical patients as a "selective" pulmonary vasodilator to optimize pulmonary hemodynamics without adverse systemic hemodynamic effects.

\section{Methods}

This protocol was approved by the Human Subjects Review Committee of the University of Colorado Health Sciences Center and the Research and Development Committee, Human Subjects Subcommittee of the Denver Veterans Affairs Medical Center. Informed consent was obtained from each participant.

Administration of inhaled NO. Inhaled NO was supplied in tanks of 800 to $2200 \mathrm{ppm}$ (Scott Medical Products, Plumsteadville, $\mathrm{Pa}$.) and was administered into the inspiratory arm of the anesthesia breathing circuit. The concentration of inhaled NO was continuously monitored at a location just proximal to the endotracheal tube by chemiluminescence (Chemiluminescence Monitor model $42 \mathrm{H}$; Thermo Environmental Instruments, Franklin, Mass.). The exhalation limb of the breathing circuit was likewise continuously monitored by chemiluminescence for nitrogen dioxide and $\mathrm{NO}_{\mathrm{x}}$ (toxic higher oxides of $\mathrm{NO}$ ).

Protocol for data collection. Twenty consecutive male patients undergoing aorta-coronary artery bypass for severe three-vessel coronary artery disease participated in the study. All patients underwent complete coronary artery revascularization, including reversed saphenous vein grafts to the right coronary artery system. Patients received preoperative medication of $0.1 \mathrm{mg} / \mathrm{kg}$ morphine sulfate and $0.4 \mathrm{mg}$ scopolamine intramuscularly 1 hour before arrival in the operating room. Ongoing drug therapy for concomitant medical problems was continued as deemed appropriate by the attending anesthesiologist.

Each patient was monitored with a five-lead electrocardiogram, a radial arterial line, and a pulmonary artery thermodilution oximetric catheter (Abbott Laboratories, Chicago, Ill.) introduced through the right internal jugular vein. To accurately measure pulmonary venous outflow pressure (left atrial pressure [LAP]) for determination of PVR, a catheter for LAP monitoring was introduced into the left atrium through the right superior pulmonary vein after the patient had been weaned from cardiopulmonary bypass. The LAP catheter was subsequently removed after completion of data collection and before chest closure. The anesthetic technique consisted of a high-dose narcotic (fentanyl) and relaxant (vecuronium) technique supplemented with intravenous midazolam. Inhalational anesthetic agents were administered only during cardiopulmonary bypass.

Data were collected in the operating room beginning approximately 20 minutes after completion of cardiopulmonary bypass but before chest closure. After weaning from bypass and protamine administration, all patients were in hemodynamically stable condition and demonstrated normal coagulation. No patients required cardiac pacing, antiarrhythmic therapy, or inotropic or vasoactive drug administration. No inhalational anesthetics were administered from the time of cessation of cardiopulmonary bypass throughout the period of data collection.

The protocol for collection of data proceeded as follows: Tidal volume was set at approximately $10 \mathrm{ml} / \mathrm{kg}$ and respiratory rate was adjusted to establish an arterial carbon dioxide tension of approximately $40 \mathrm{~mm} \mathrm{Hg}$ and an arterial $\mathrm{pH}$ of approximately $7.400^{6}$ To avoid changes in pulmonary hemodynamics resulting from changes in ventilatory patterns, ventilator settings were not subsequently altered during the study period. Fraction of inspired oxygen was maintained at a mean of 0.97 (range 0.94 to 0.99 ), and no patient had positive end-expiratory pressure applied at any point during the study period. Arterial oxygen tension $\left(\mathrm{PO}_{2}\right)$ was therefore maintained at greater than $275 \mathrm{~mm} \mathrm{Hg}$ throughout the study period to avoid any influence of hypoxemia on pulmonary vascular tone. Arterial and mixed venous blood gas samples were obtained at each point of data collection. The hemodynamic variables measured and recorded were heart rate, mean SAP, MPAP, central venous pressure, LAP, and thermodilution $\mathrm{CO}$ (mean of three values). These allowed mathematic derivation of PVR, SVR, cardiac index, right ventricular stroke work index (RVSWI), and transpulmonary gradient (TPG).

The protocol for data collection is shown in Fig. 1. After placement of the LAP line and with the patient in a hemodynamic steady state, baseline hemodynamic variables were determined. $\mathrm{NO}$ at a concentration of $20 \mathrm{ppm}$ was then added to the ventilatory circuit. After 10 minutes of inhaled $20 \mathrm{ppm} \mathrm{NO}$, hemodynamic variables were determined. The concentration of inhaled NO was then increased to $40 \mathrm{ppm}$. After 10 minutes, hemodynamic variables were once again determined. Inhaled NO was then stopped. After 10 minutes, hemodynamic post- 
inhaled NO data were collected. The LAP line was then removed under direct vision and its insertion site in the right superior pulmonary vein was determined to be hemostatic. Methemoglobin level was determined before and after data collection.

See Appendix for formulas used for calculation of hemodynamic parameters.

Statistical analysis. Statistical analyses were performed with a Macintosh Quadra 650 Computer (Apple Computer, Inc., Cupertino, Calif.) and StatView software (Brain Power, Inc., Calabasas, Calif.). Data are presented as mean \pm standard error of the mean. Statistical evaluation used standard analysis of variance in conjunction with the Student-Newman-Keuls multiple comparisons procedure. A $p$ value less than 0.05 was accepted as statistically significant.

\section{Results}

The study population comprised 20 male patients, with subject demographics listed in Table I. All patients had a history of cigarette smoking; none, however, demonstrated clinical or radiographic evidence of significant chronic pulmonary disease. No subjects had preoperative pulmonary hypertension. All subjects were taking at least one aspirin daily before operation.

Table II lists the arterial and mixed venous blood gas values along with the hemodynamic variables determined at each point of data collection. There were no changes in arterial $\mathrm{pH}$, arterial $\mathrm{Po}_{2}$, or arterial carbon dioxide tension throughout the study period. Likewise, there were no significant changes in heart rate, central venous pressure, or LAP throughout the period of data collection. Methemoglobin level was unchanged after administration of inhaled NO.

Inhaled $20 \mathrm{ppm}$ NO produced a significant reduction in MPAP without decrease in mean SAP. As shown in Fig. 2, $20 \mathrm{ppm}$ NO produced a $24 \%$ decrease in MPAP: MPAP was reduced from to 29 \pm 1 to $22 \pm 1 \mathrm{~mm} \mathrm{Hg}(p<0.05)$. Increasing the concentration of inhaled NO to $40 \mathrm{ppm}$ produced a small additional decrease in MPAP to $21 \pm 1 \mathrm{~mm}$ $\mathrm{Hg}$. MPAP returned to $29 \pm 1 \mathrm{~mm} \mathrm{Hg}$ after withdrawal of inhaled NO $(p<0.05$ vs during inhalation; not different from before NO). On the other hand, mean SAP was not changed during NO inhalation (Fig. 2).

As shown in Fig. 3, these changes in MPAP were produced without significant changes in pulmonary arterial blood flow (CO) or pulmonary venous outflow pressure (LAP). The changes in pulmonary arterial pressure (MPAP) therefore occurred as a result of pulmonary vasorelaxation. In fact, as shown in Fig. 4, inhaled NO produced
Table I. Patient demographics

\begin{tabular}{lc} 
No. of patients & 20 \\
Age (yr) & $57 \pm 6$ \\
Body surface area $\left(\mathrm{m}^{2}\right)$ & $1.8 \pm 0.05$ \\
Aortic crossclamp time (min) & $91 \pm 17$ \\
Cardiopulmonary bypass time (min) & $124 \pm 18$ \\
Tidal volume (ml $/ \mathrm{kg}$ ) & $10 \pm 0.5$ \\
Respiratory rate (breaths $/ \mathrm{min})$ & 12 \\
\hline
\end{tabular}

Values are mean \pm standard error of the mean.

a significant reduction in TPG. Before inhaled $\mathrm{NO}$, the TPG was $21 \pm 1 \mathrm{~mm} \mathrm{Hg}$. This was significantly lowered with $20 \mathrm{ppm}$ NO by $33 \%$ to $14 \pm 1 \mathrm{~mm} \mathrm{Hg}(p<0.05)$. The TPG was $13 \pm 1$ $\mathrm{mm} \mathrm{Hg}$ during administration of $40 \mathrm{ppm} \mathrm{NO}$ and returned to $21 \pm 1 \mathrm{~mm} \mathrm{Hg}$ after NO administration was stopped ( $p<0.05$ versus during inhalation of NO; not different from before NO).

This pulmonary vasorelaxation produced a reduction in PVR (Fig. 5). Inhaled 20 ppm NO significantly reduced PVR from $343 \pm 30$ to $233 \pm 25$ dynes $\cdot \mathrm{sec} \cdot \mathrm{cm}^{-5}$, a $32 \%$ reduction in PVR $(p<$ $0.05)$. This reduction in PVR was not greater with 40 ppm NO. With cessation of NO administration, PVR returned to $342 \pm 30$ dynes $\cdot \mathrm{sec} \cdot \mathrm{cm}^{-5}(p<$ 0.05 versus during $\mathrm{NO}$; not different from before $\mathrm{NO}$ ). At the same time, there was no change in SVR during NO administration (Fig. 5).

These changes in PVR resulted in a significant reduction in RVSWI. As shown in Fig. 6, RVSWI was significantly reduced from $12.1 \pm 0.5 \mathrm{gm} \cdot \mathrm{m}^{-2}$ before inhalation of NO to $8.9 \pm 0.5 \mathrm{gm} \cdot \mathrm{m}^{-2}$ during inhalation of $20 \mathrm{ppm}$ NO $(p<0.05)$. At 40 ppm NO, RVSWI was $8.6 \pm 0.5 \mathrm{gm} \cdot \mathrm{m}^{-2}$. After inhaled NO was stopped, RVSWI returned to 12.2 $\pm 0.5 \mathrm{gm} \cdot \mathrm{m}^{-2}(p<0.05 \mathrm{vs}$ during NO; not different from before $\mathrm{NO}$ ).

\section{Discussion}

The results of this study demonstrate that inhaled NO after aorta-coronary bypass operations produced significant reductions in MPAP, TPG and PVR. In turn, these effects on the pulmonary circulation resulted in a significant reduction in RVSWI. In this group of patients without severe pulmonary hypertension, inhalation of $20 \mathrm{ppm}$ NO lowered PAP to normal levels; the reductions in PVR and PAP were not augmented by increasing inhaled NO from 20 to $40 \mathrm{ppm}$. This pulmonary vasorelaxation was achieved without changes in SVR or mean SAP.

Patients undergoing cardiac operations offered a unique opportunity to examine the influence of inhaled NO on PVR. A homogeneous group, pa- 


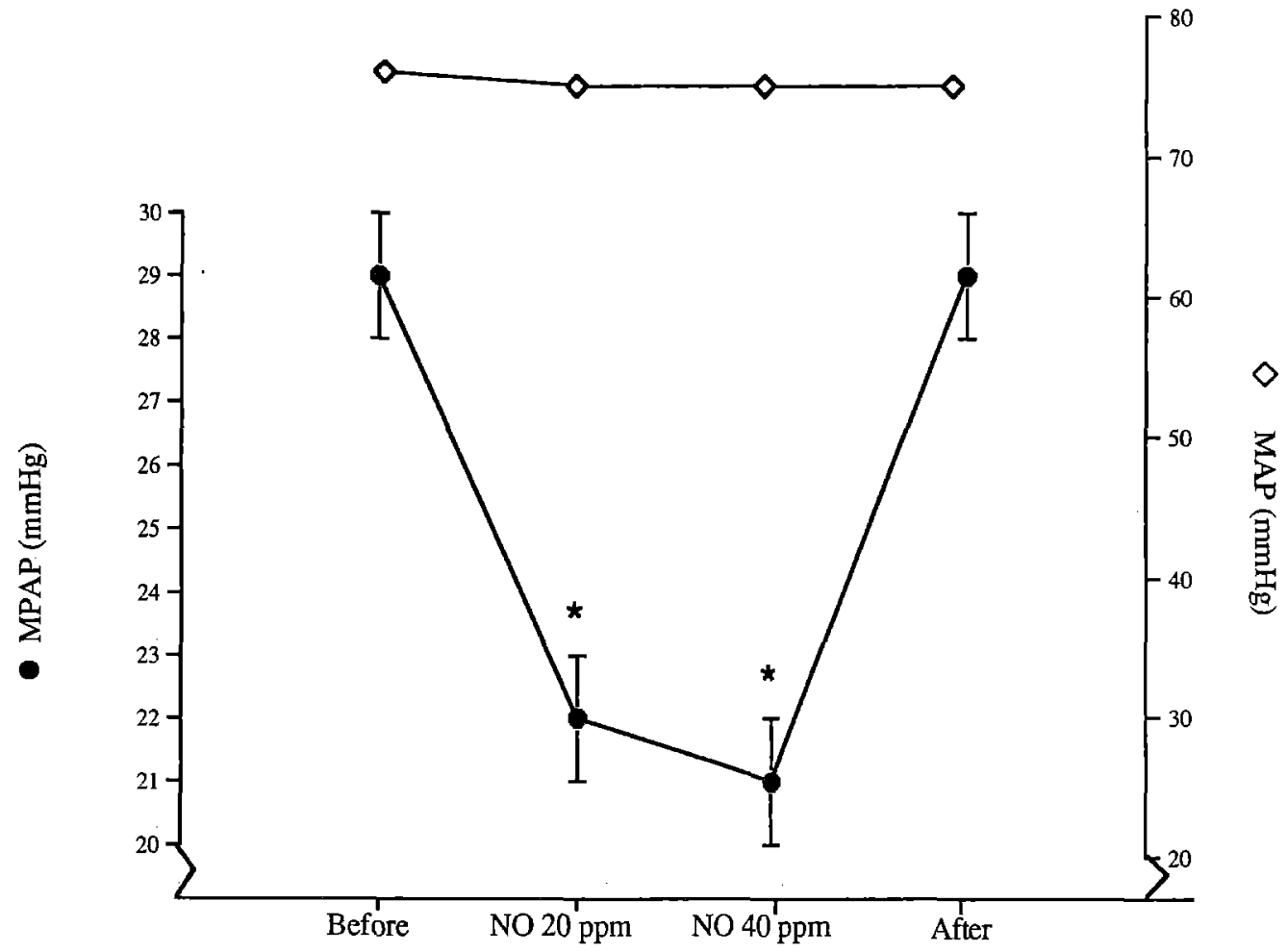

Fig. 2. Effect of inhaled NO on MPAP and mean SAP (MAP). Inhaled NO produced a significant decrease in MPAP without change in mean SAP. Asterisk represents $p<0.05$ versus before and after NO.

Table II. Hemodynamic data

\begin{tabular}{|c|c|c|c|c|}
\hline & Before & $20 \mathrm{ppm} \mathrm{NO}$ & $40 \mathrm{ppm} \mathrm{NO}$ & After NO \\
\hline Temperature $\left({ }^{\circ} \mathrm{C}\right)$ & $37.3 \pm 0.5$ & $37.2 \pm 0.5$ & $37.2 \pm 0.5$ & $37.2 \pm 0.5$ \\
\hline Hemoglobin $(\mathrm{gm} / \mathrm{dl})$ & $9.6 \pm 0.3$ & $9.7 \pm 0.3$ & $9.6 \pm 0.4$ & $9.6 \pm 0.4$ \\
\hline Arterial pH & $7.39 \pm 0.01$ & $7.41 \pm 0.01$ & $7.39 \pm 0.01$ & $7.40 \pm 0.01$ \\
\hline Arterial $\mathrm{PCO}_{2}(\mathrm{~mm} \mathrm{Hg})$ & $39 \pm 4$ & $42 \pm 4$ & $40 \pm 3$ & $40 \pm 2$ \\
\hline Arterial $\mathrm{PO}_{2}(\mathrm{~mm} \mathrm{Hg})$ & $310 \pm 18$ & $300 \pm 12$ & $305 \pm 10$ & $316 \pm 12$ \\
\hline Mixed venous $\mathrm{pH}$ & $7.33 \pm 0.01$ & $7.35 \pm 0.01$ & $7.33 \pm 0.01$ & $7.34 \pm 0.01$ \\
\hline Mixed venous $\mathrm{PCO}_{2}(\mathrm{~mm} \mathrm{Hg})$ & $47 \pm 3$ & $46 \pm 4$ & $45 \pm 3$ & $46 \pm 3$ \\
\hline Mixed venous $\mathrm{PO}_{2}(\mathrm{~mm} \mathrm{Hg})$ & $40 \pm 3$ & $39 \pm 3$ & $41 \pm 2$ & $40 \pm 3$ \\
\hline Heart rate (beats/min) & $93 \pm 6$ & $94 \pm 6$ & $92 \pm 5$ & $93 \pm 7$ \\
\hline $\mathrm{CVP}(\mathrm{mm} \mathrm{Hg})$ & $10 \pm 1$ & $9 \pm 1$ & $9 \pm 1$ & $9 \pm 1$ \\
\hline $\mathrm{LAP}(\mathrm{mm} \mathrm{Hg})$ & $8 \pm 1$ & $8 \pm 1$ & $8 \pm 1$ & $8 \pm 1$ \\
\hline $\mathrm{MPAP}(\mathrm{mm} \mathrm{Hg})$ & $29 \pm 1$ & $22 \pm 1^{*}$ & $21 \pm 1^{*}$ & $29 \pm 1$ \\
\hline TPG $(\mathrm{mm} \mathrm{Hg})$ & $21 \pm 1$ & $14 \pm 1^{*}$ & $13 \pm 1^{*}$ & $21 \pm 1$ \\
\hline $\mathrm{CO}(\mathrm{L} / \mathrm{min})$ & $4.9 \pm 0.5$ & $4.8 \pm 0.5$ & $4.7 \pm 0.5$ & $4.9 \pm 0.5$ \\
\hline Mean SAP $(\mathrm{mm} \mathrm{Hg})$ & $76 \pm 5$ & $75 \pm 6$ & $75 \pm 5$ & $75 \pm 5$ \\
\hline Methemoglobin $(\mathrm{gm} / \mathrm{dl})$ & $1.8 \pm 0.1$ & $1.9 \pm 0.1$ & $1.9 \pm 0.1$ & $1.9 \pm 0.1$ \\
\hline
\end{tabular}

$P_{\mathrm{CO}_{2}}$, Carbon dioxide tension; $\mathrm{CVP}$, central venous pressure; $T P G$, transpulmonary gradient. Values are mean \pm standard error of the mean. ${ }^{*} p<0.05$ vs before and after inhaled NO.

tients undergoing aorta-coronary bypass grafting, could be studied. Control of many variables that affect PVR was available with this select group of patients. Surgical access allowed accurate measure- ment of pulmonary venous outflow pressure (LAP) for calculation of PVR. ${ }^{7}$ Anesthesia and mechanical ventilated of these patients allowed maintenance of a constant rate of ventilation and tidal volume to 


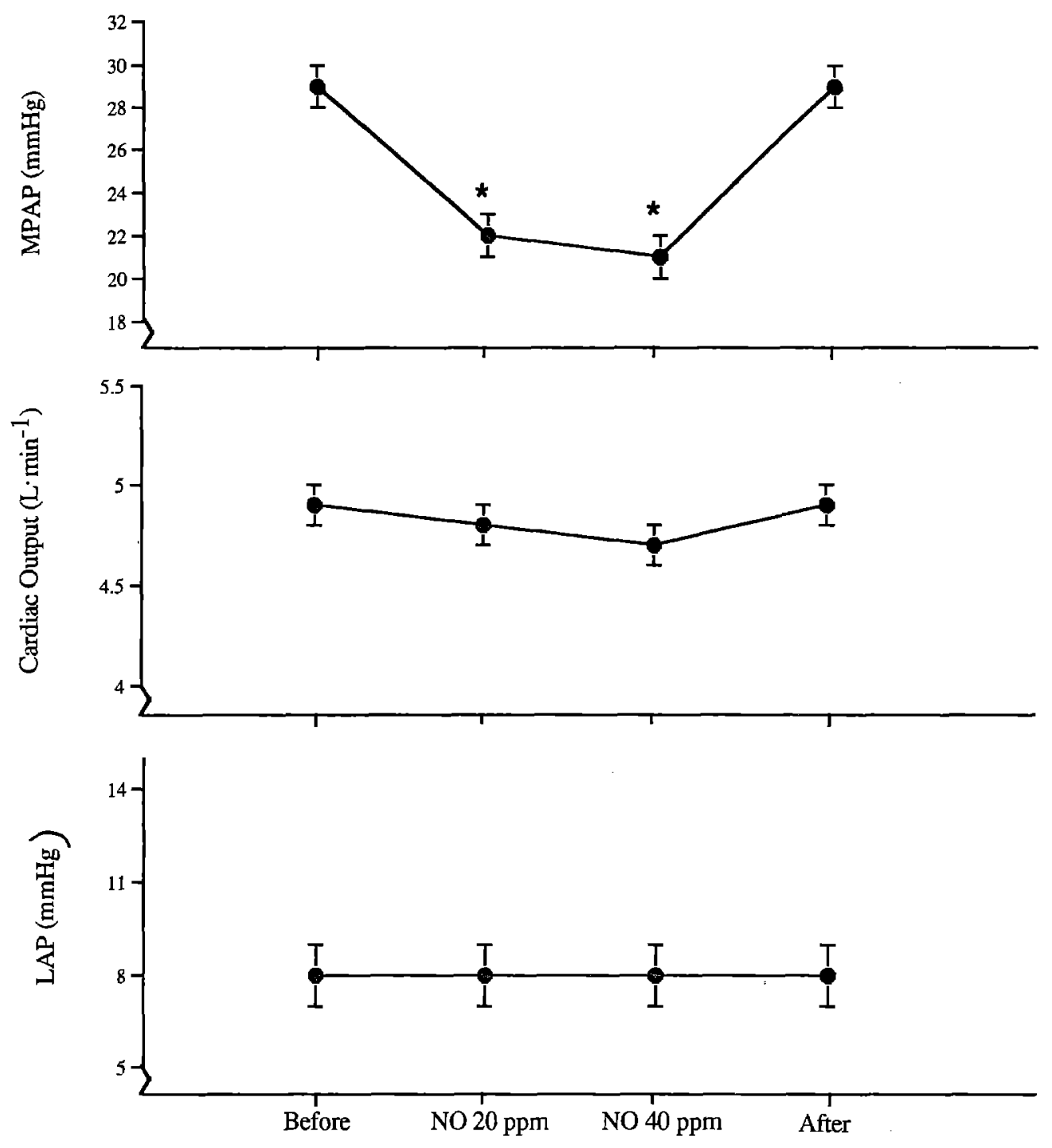

Fig. 3. Effect of inhaled NO on CO and LAP. Inhaled NO produced no changes in pulmonary arterial flow (CO) or pulmonary venous outflow pressure (LAP). These data indicate that the reduction in MPAP was produced by pulmonary vasorelaxation. Asterisk represents $p<0.05$ versus before and after NO.

avoid mechanical alterations of PVR. ${ }^{8}$ Furthermore, arterial $\mathrm{PO}_{2}$ could be well controlled and changes in acid-base status could be avoided. 6,9

In our protocol, a standard cardiac anesthetic technique was employed. Intravenous anesthetic agents were administered only before cardiopulmonary bypass, and inhalational anesthetic agents were not administered after cessation of cardiopulmonary bypass until after the period of data collection. Any influence of anesthesia on PVR can therefore be assumed to have been held constant. Although the anesthetic technique may influence the response of the pulmonary vasculature to inhaled NO, this in- fluence was held constant during the period of data collection. In addition, to optimize clinical relevance, patients were examined early after operation.

The principal intracellular mechanisms of pulmonary vasodilators are ultimately mediated through either guanosine 3',5'-cyclic monophosphate (cGMP) or adenosine $3^{\prime}, 5^{\prime}$-cyclic monophosphate. ${ }^{10}$ Pharmacologic agents mediated by cGMP that have been employed as pulmonary vasodilators in cardiac surgical patients include nitroglycerin and sodium nitroprusside ${ }^{11}$; agents mediated by cyclic adenosine monophosphate include prostaglandin $\mathrm{E}_{1}$, dobutamine, amrinone, and isoproterenol. ${ }^{12-15}$ All of these agents 


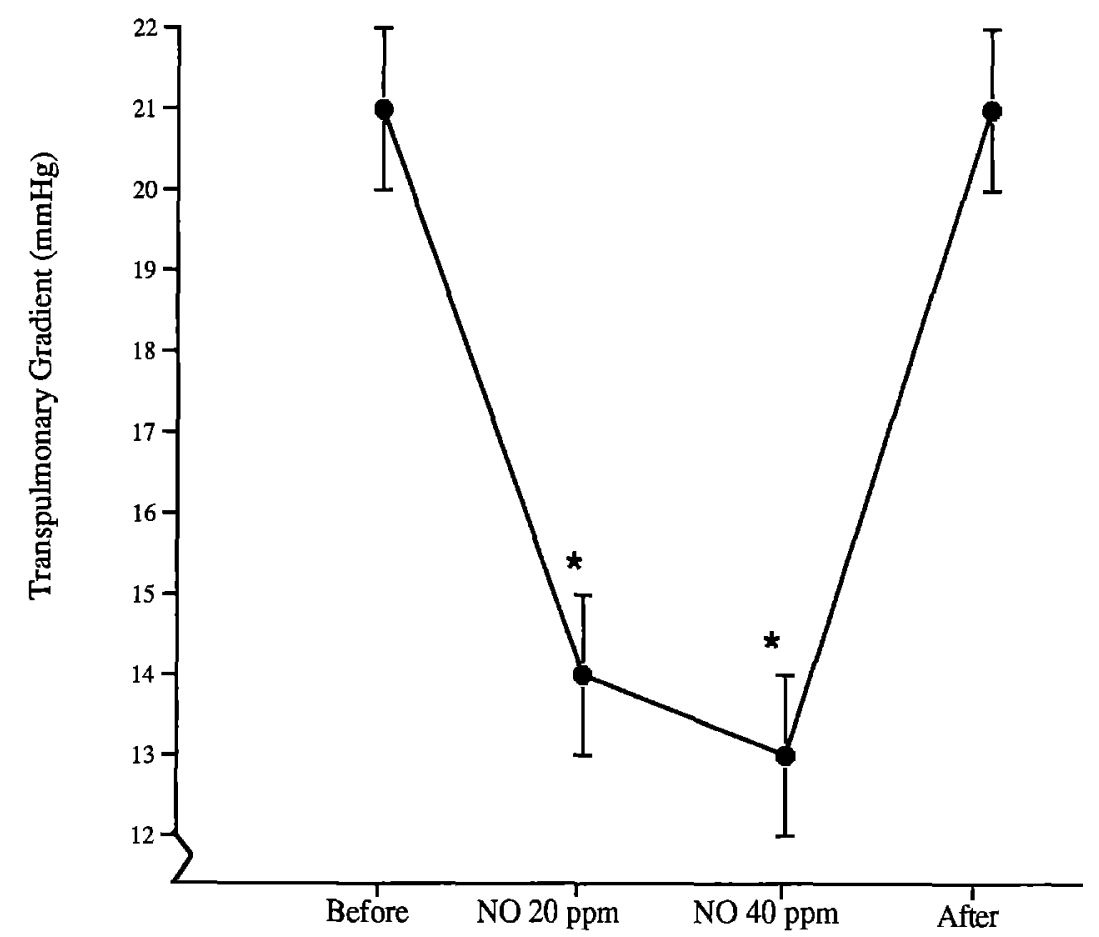

Fig. 4. Effect of inhaled NO on TPG. Asterisk represents $p<0.05$ versus before and after NO.

are administered intravenously, and all clinically produce vasodilation of both the systemic and pulmonary vascular beds. In patients with increased PVR, such nonselective vasodilation may be hazardous: significant hypotension may result if the reduction of SVR is greater than the reduction in PVR. ${ }^{1,2}$ Such hypotension may in fact be life-threatening if the SAP is lowered enough to decrease coronary arterial perfusion pressure, resulting in right ventricular ischemia and failure. ${ }^{16,17}$ Further, the clinical effectiveness of intravenously administered pulmonary vasodilators is often limited by the fact that they increase intrapulmonary shunt fraction and thereby lower arterial $\mathrm{PO}_{2} \cdot{ }^{18}$

Inhaled NO may offer a significant advantage as a pulmonary vasodilator. Once administered into the alveoli by inhalation, it diffuses rapidly across the alveolar-capillary membrane into the subjacent vascular smooth muscle to stimulate guanylate cyclase, generating cGMP and producing pulmonary vascular smooth muscle relaxation. ${ }^{19,20}$ Once NO diffuses through the smooth muscle cell into the capillary lumen, it is immediately bound to hemoglobin in erythrocytes as methemoglobin; the affinity of hemoglobin for NO is approximately 3000 times greater than the affinity of hemoglobin for oxygen. ${ }^{20}$ Methemoglobin is reduced to nitrates by methemo- globin reductase, found in erythrocytes. It is estimated that most of the nitrates and nitrites found in blood result from the metabolism of endogenous NO. ${ }^{20}$ In this way, the vasodilating actions of inhaled $\mathrm{NO}$ are focused in the pulmonary circulation; it is metabolized before it reaches the systemic circulation.

Most of the human data relating to the use of inhaled NO have been obtained from patients with both hypoxemia and pulmonary vasoconstriction. Inhaled NO has been used clinically as a pulmonary vasodilator in infants with persistent pulmonary hypertension. In such infants, severe pulmonary vasoconstriction is associated with hypoxemia and systemic hypotension. By dilating the pulmonary circulation, inhaled NO has been shown to improve oxygenation and increase systemic blood pressure. ${ }^{21,22}$ Inhaled NO has also proved to be an effective pulmonary vasodilator in children with acute pulmonary insufficiency. ${ }^{23}$ Although the pediatric pulmonary vascular bed is prone to avid pulmonary vasoconstriction, inhaled NO has been shown to vasodilate hypoxic pulmonary vasoconstriction in adults as well. ${ }^{24}$ In fact, the most extensive clinical experience with inhaled NO has been in patients with ARDS., ${ }^{3,25-28}$ Inhalational administration of NO directs the agent into ventilated alveoli, where it acts locally to vasodilate. This local vasodilation diverts pulmonary blood flow away from poorly 


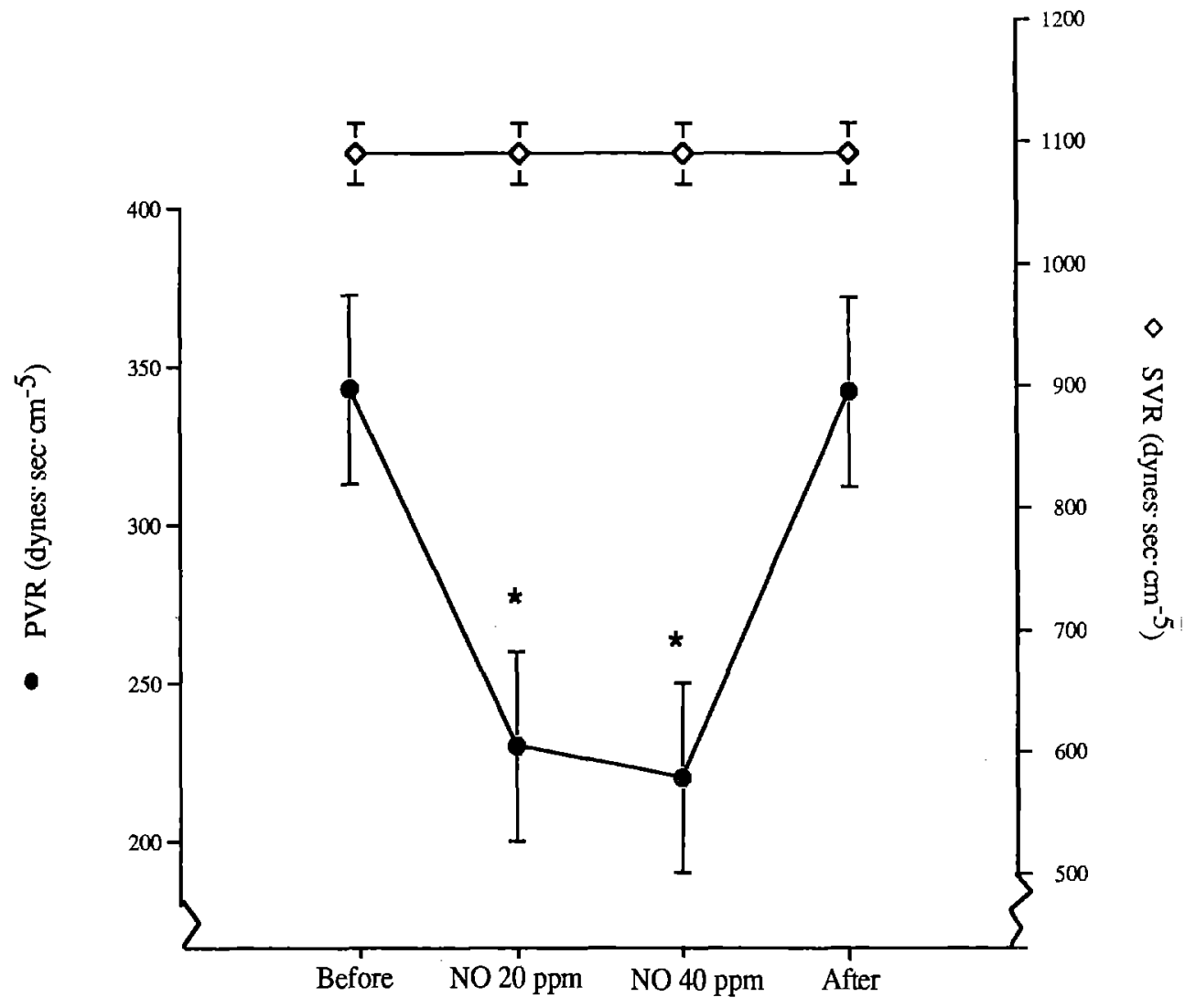

Fig. 5. Effect of inhaled NO on pulmonary and SVR. Inhaled NO produced a significant reduction in PVR without change in SVR. Asterisk represents $p<0.05$ versus before and after NO.

ventilated regions of the lung, thereby optimizing ventilation-perfusion matching. In most series of patients with ARDS, inhaled NO is reported to simultaneously improve oxygenation and reduce PAP. Because hypoxemia is such an important cause of pulmonary vasoconstriction, however, it is unclear from these data what effect, if any, inhaled NO has on pulmonary vasoconstriction that is not associated with hypoxemia. Of particular interest, as many as one third of patients with ARDS have not shown improved oxygenation in response to inhaled NO. In these nonresponding patients, inhaled NO has minimal effect on PAP. ${ }^{3}$

Unlike patients with ARDS, cardiac surgical patients may have pulmonary vasoconstriction not associated with hypoxemia. Unfortunately, relatively few data are available regarding the use of inhaled NO after cardiac operations. When administered before operation to patients with congenital heart disease and pulmonary hypertension, inhaled NO lowered PAP without lowering SAP. ${ }^{29}$ In postoperative pediatric cardiac surgical patients with severe pulmonary hypertension refractory to conventional therapy, inhaled NO lowered MPAP in 12 of 17 patients. Administration of inhaled NO was associated, however, with a significant decrease in mean SAP in four of these 17 patients $(24 \%) .^{5}$ In adults with pulmonary hypertension after mitral valve replacement, inhaled NO produced a modest reduction in PAP. ${ }^{30}$ Patients with pulmonary hypertension from mitral valve disease frequently have structural changes in the pulmonary vascular bed, however, which may contribute to increased PVR yet may not be amenable to vasodilator therapy. In a study of 20 adult cardiac surgical patients, 16 of whom underwent single- or double-valve replacement and four of whom underwent coronary artery bypass grafting, the response to inhaled NO was found to be unchanged by cardiopulmonary bypass. The responsiveness of the pulmonary vascular bed to inhaled NO in these patients was variable, however, and depended on the level of PVR before administration of inhaled NO. ${ }^{31}$ In the first report of the use of inhaled NO in human beings, Pepke-Zaba 


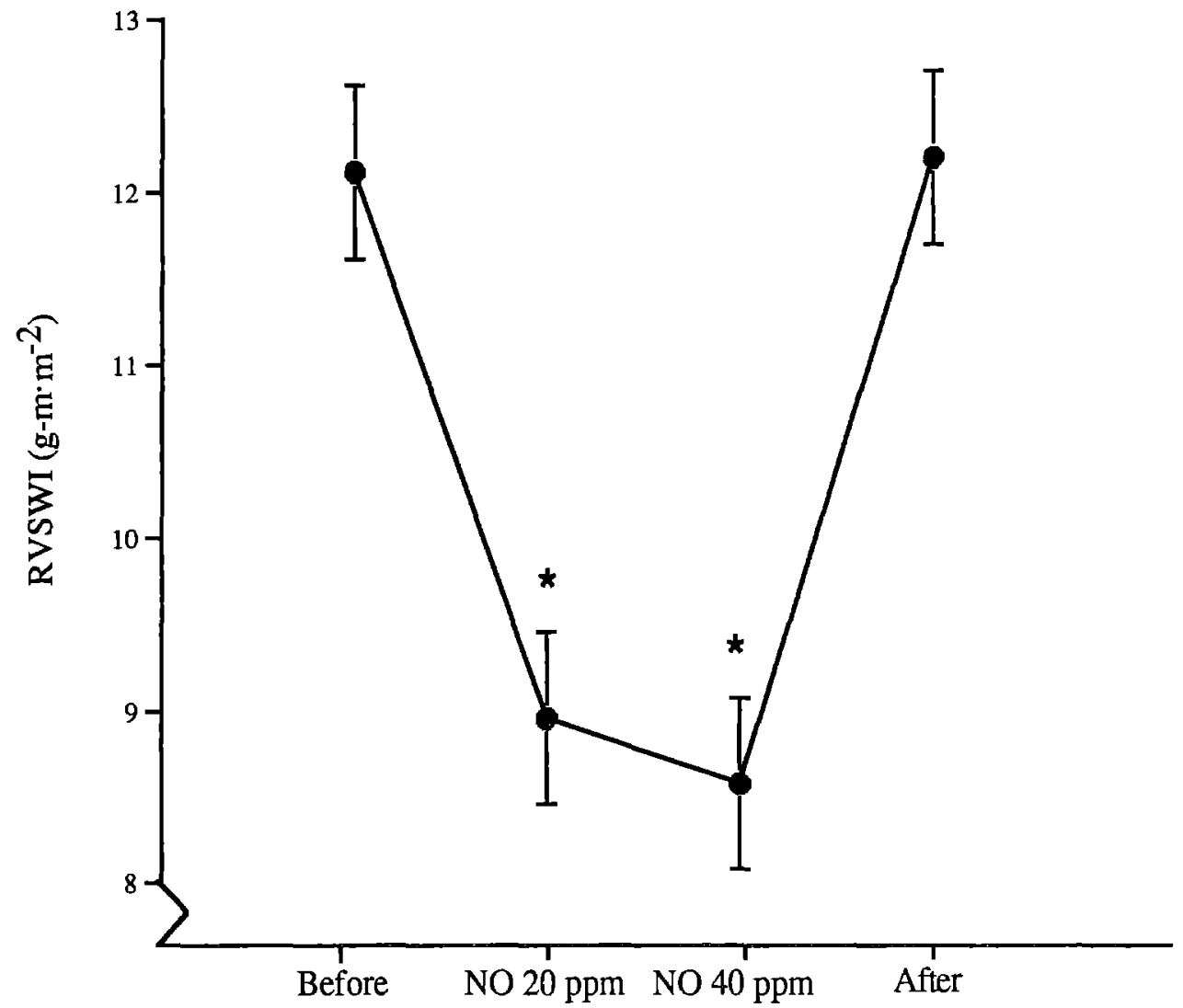

Fig. 6. Effect of inhaled NO on RVSWI. Asterisk represents $p<0.05$ versus before and after NO.

and coworkers ${ }^{32}$ reported a significant fall in PVR in patients (including seven patients with mitral valve disease and three with ischemic heart disease) who breathed inhaled NO in the cardiac catheterization suite during preoperative evaluation. Lindberg and colleagues $^{33}$ as well as Snow and colleagues, ${ }^{34}$ however, reported minimal effect of inhaled NO on PVR after aorta-coronary bypass operations in adult cardiac surgical patients in whom the starting PAP was low. The findings of our study confirm that inhaled NO is an effective pulmonary vasodilator in adult cardiac surgical patients with elevated PAP $(29 \pm 1 \mathrm{~mm} \mathrm{Hg})$ after cardiopulmonary bypass. Further, this pulmonary vasodilation was accomplished in patients without hypoxemia. It is possible that the reduction of PAP and PVR found in our study but not found in the studies by Lindberg and associates $^{33}$ and Snow and colleagues ${ }^{34}$ was a function of the higher PAP in our study. The reasons for the higher pulmonary vascular tone in our study are unclear, but this higher PAP may reflect differences in anesthetic or perfusion techniques, duration of cardiopulmonary bypass, or the time interval after completion of cardiopulmonary bypass before data collection.

Our study was designed to examine the acute effects of inhaled NO administration. One may not draw conclusions therefore regarding the effects of prolonged exposure. NO is a potentially toxic gas; inhalation of greater than $1000 \mathrm{ppm}$ has been shown to cause acute lung injury in laboratory animals. ${ }^{35} \mathrm{In}$ human beings, NO is believed to cause silo-filler's disease. ${ }^{20}$ Prolonged administration of inhaled NO therefore requires chemiluminescence monitoring to accurately measure the concentration of inhaled NO and to measure the exhaled concentration of its toxic metabolite, nitrogen dioxide. Blood samples are also required to measure methemoglobin concentration. During the brief administration of inhaled NO in our study, there were no changes in nitrogen dioxide or methemoglobin. Despite these potential toxicities, prolonged administration of inhaled NO to patients with ARDS in concentrations as great as $80 \mathrm{ppm}$ for durations as long as 53 days 
have not been found to produce toxic effects in the lung. ${ }^{4}$ Nonetheless, a trial of inhaled NO was reported to precipitate pulmonary edema in a patient with stable heart failure. ${ }^{36}$ Of particular concern in cardiac surgical patients is the possibility that inhaled NO may depress myocardial contractility. Although no changes in $\mathrm{CO}$ were found with inhaled $\mathrm{NO}$ in our study, further investigation is required to determine the influence of inhaled NO on cardiac function.

Net pulmonary vascular smooth muscle tone results from the mechanistic balance of vasoconstriction and vasorelaxation. In the normal lung, the low pulmonary vascular smooth muscle tone may be due at least in part to basal release of endotheliumderived NO. ${ }^{37}$ The pulmonary vasoconstricting effects of cardiopulmonary bypass are well recognized. After cardiopulmonary bypass, increased pulmonary vascular tone may be caused by increased levels of circulating or local vasoconstricting agonists. ${ }^{38}$ Pulmonary vascular endothelial dysfunction may contribute to this pulmonary vasoconstriction; impairment of endothelium-dependent cGMPmediated pulmonary vasorelaxation has recently been described after cardiopulmonary bypass. ${ }^{39} \mathrm{Be}-$ cause inhaled NO achieves pulmonary vascular smooth relaxation independently of the endothelium, it may offer a mechanistic advantage for use as a pulmonary vasodilator after cardiopulmonary bypass.

In summary, inhaled NO produced a significant reduction in both PAP and PVR in patients after cardiac operations without reducing SAP or SVR. In this study, there were no differences in the hemodynamic effects of 20 and $40 \mathrm{ppm}$ NO. In patients with higher PVR and PAP, however, concentrations as high as $80 \mathrm{ppm}$ may be required. We conclude that inhaled NO may be clinically valuable as a "selective" pulmonary vasodilator for cardiac surgical patients. It may be particularly valuable for patients with dysfunction of the right side of the heart by selectively lowering right ventricular afterload, thereby optimizing function of the right side of the heart.

\section{REFERENCES}

1. Packer M, Greenberg B, Massie B, Dash H. Deleterious effects of hydralazine in patients with pulmonary hypertension. N Engl J Med 1982;306:1326-31.

2. Kadowitz PJ, Hyman AL. Hydralazine and the treatment of primary pulmonary hypertension. N Engl J Med 1982;306: 1357-9.

3. McIntyre RC Jr, Moore FA, Moore EE, Piedalue F, Hoenel JS, Fullerton DA. Inhaled nitric oxide variably improves oxy- genation and pulmonary hypertension in patients with acute respiratory distress syndrome. J Trauma 1995 [In press].

4. Rossaint R, Falke K, Lopez F, Slama K, Pison U, Zapol WM. Inhaled nitric oxide for the adult respiratory distress syndrome. N Engl J Med 1993;328:399-405.

5. Journais $D$, Pouard $P$, Mauriat $P$, Malhère $T$, Vouhé $P$, Safran D. Inhaled nitric oxide as a therapy for pulmonary hypertension after operations for congenital heart defects. J Thorac Cardiovasc Surg 1994;107:1129-35.

6. Fullerton DA, Kirsen LE, St Cyr JA, Kinnard T, Whitman GJ. Influence of hydrogen ion concentration versus carbon dioxide tension on pulmonary vascular resistance following cardiac operation. J Thorac Cardiovasc Surg 1993;106:528-36.

7. Morris AH, Chapman RH, Gardner RN. Frequency of technical problems encountered in the measurement of pulmonary artery wedge pressure. Crit Care Med 1984;12:16470.

8. Fishman AP. Pulmonary circulation. In: Fishman AP, ed. Handbook of physiology: the respiratory system, vol 1. Bethesda, Maryland: American Physiologic Society, 1985:chap 3, 93-165.

9. Fullerton DA, Kirson LE, St Cyr JA, Albert JD, Whitman GJ. The influence of respiratory acid-base status on adult pulmonary vascular resistance before and after cardiopulmonary bypass. Chest 1993;93:1091-5.

10. Fullerton DA, Hahn AR, Banerjee A, Harken AH. Pulmonary vascular smooth muscle relaxation by cGMP- versus cAMP-mediated mechanisms. J Surg Res 1994:57:259-63.

11. Bates JN, Baker MT, Guerra R Jr, Harrison DG. Nitric oxide generation from nitroprusside by vascular tissue: evidence that reduction of the nitroprusside anion and cyanide loss are required. Biochem Pharmacol 1991;42:S157-65.

12. Camara ML, Aris A, Alvarez J, Padro JM, Caralps JM. Hemodynamic effects of prostaglandin $E_{1}$ and isoproterenol early after cardiac operations for mitral stenosis. J Thorac Cardiovase Surg 1992;103:1177-85.

13. Tinker JH. Dobutamine for inotropic support during emergence from cardiopulmonary bypass. Anesthesiology 1976; 44:281-8.

14. D'Ambra MN, LaRaia PJ, Phibin DM, Watkins WD, Hilgenberg $A D$, Buckley MJ. Prostaglandin $E_{1}$ : a new therapy for refractory right heart failure and pulmonary hypertension after mitral valve replacement. J Thorac Cardiovasc Surg 1985;89:567-72.

15. Deeb GM, Bolling SF, Guynn TP, Nicklas JM. Amrinone versus conventional therapy in pulmonary hypertensive patients awaiting cardiac transplantation. Ann Thorac Surg 1989;48:665-9.

16. Vlahakes GJ, Turley K, Hoffman JI. The pathophysiology of failure in acute right ventricular hypertension: hemodynamic and biochemical correlations. Circulation 1981;63:87-95.

17. Prewitt RM, Ghigone M. Treatment of right ventricular dysfunction in acute respiratory failure. Crit Care Med 1983;11:346-52.

18. Weigelt JA, Gewertz BL, Aurbakken CM, Snyder WH. Pharmacologic alterations in pulmonary artery pressure in the adult respiratory distress syndrome. J Surg Res 1982;32:243-8.

19. Ignarro L. Biological actions and properties of endothelialderived nitric oxide formed and released from artery and vein. Circ Res 1989;65:1-21.

20. Zapol WM, Hurford WE. Inhaled nitric oxide in the adult 
respiratory distress syndrome and other lung diseases. New Horizons 1993;1:638-50.

21. Kinsella JP, Neish SR, Shaffer E, Abman SH. Low-dose inhalational nitric oxide in persistent pulmonary hypertension of the newborn. Lancet 1992;340:819-20.

22. Roberts JD Jr. Inhaled nitric oxide for treatment of pulmonary artery hypertension in the newborn and infant. Crit Care Med 1993;21:S374-5.

23. Abman SH, Griebel JL, Parker DK, Schmidt JM, Swanton D, Kinsella JP. Acute effects of inhaled nitric oxide in children with severe hypoxemic respiratory failure. J Pediatr 1994;124: 881-4.

24. Frostell CG, Blomqvist $H$, Hedenstierna $G$, Lundberg J, Zapol WM. Inhaled nitric oxide selectively reverses human hypoxic pulmonary vasoconstriction without causing systemic vasodilation. Anesthesiology 1993;78:427-35.

25. Rossaint R, Gerlach H, Schmidt-Ruhnke H, et al. Efficacy of inhaled nitric oxide in patients with severe ARDS. Chest 1995;107:1107-15.

26. Ricou B, Suter PM. Variable effects on nitric oxide (NO) in ARDS patients. Am Rev Respir Dis 1993;147:A350.

27. Bigatello LM, Huford WE, Kacmarek RM, et al. Inhaled nitric oxide is a selective vasodilator in septic patients with severe ARDS. Anesthesiology 1994;80:761-70.

28. Gerlach H, Rossaint R, Pappert D, et al. Time-course and dose-response of nitric oxide inhalation for systemic oxygenation and pulmonary hypertension in patients with adult respiratory distress syndrome. Eur J Clin Invest 1993;23:499502.

29. Robert JD Jr, Lang P, Bigatello LM, Vlahakes GJ, Zapol WM. Inhaled nitric oxide in congenital heart disease. Circulation 1993;87:447-53.

30. Girard C, Lehot JJ, Pannetier JC, Filley S, Ffrench P, Estanove $\mathrm{S}$. Nitric oxide after mitral valve replacement in patients with chronic pulmonary artery hypertension. Anesthesiology 1992;77:880-3.

31. Rich GF, Murphy GD, Roos CM, Johns RA. Inhaled nitric oxide: selective pulmonary vasodilation in cardiac surgical patients. Anesthesiology 1993;78:1028-35.

32. Pepke-Zaba J, Higenbottam TW, Dinh-Xuan AT, Stone D, Wallwork J. Inhaled nitric oxide as a cause of selective pulmonary vasodilation in pulmonary bypertension. Lancet 1991;338:1173-4.

33. Lindberg L, Larsson A, Olsson SC, Nordstrom L. Nitric oxide gives maximal response after coronary artery bypass surgery. J Cardiothorac Vasc Anesth 1994;8:182-7.

34. Snow DJ, Ghosh GS, Foubert L, et al. Inhaled nitric oxide in patients with normal and increased pulmonary vascular resistance after cardiac surgery. Br J Anaesth 1994;72:185-9.

35. Stavert DM, Lehnert BE. Nitric oxide and nitrogen dioxide as inducers of acute pulmonary injury when inhaled at relatively high concentrations for brief periods. Inhal Toxicol 1990;2:53-67.

36. Bocchi EA, Bacal F, Auler JO, de Carvalho MJ, Bellotti G, Pileggi F. Inhaled nitric oxide leading to pulmonary edema in stable severe heart failure. Am J Cardiol 1994;74:70-4.

37. McIntyre RC Jr, Harken AH, Fullerton DA. Mechanisms of pulmonary vasomotor function in normal and injured lung. Surgery 1994;115:273-5.

38. Downing SW, Edmunds LH. Release of vasoactive substances during cardiopulmonary bypass. Ann Thorac Surg 1992;54:1236-43.
39. Wessel DL, Adatia I, Giglia TM, Thompson JE, Kulik TJ. Use of inhaled nitric oxide and acetylcholine in the evaluation of pulmonary hypertension and endothelial function after cardjopulmonary bypass. Circulation 1993;88:2128-38.

\section{Discussion}

Dr. Jorge A. Wernly (Albuquerque, N.M.). I congratulate Fullerton and associates on an elegant, well-controlled clinical study demonstrating the efficacy of NO in controlling PVR after cardiac operations. Specifically, I congratulate Dr. Fullerton for a beautiful presentation. He has presented the data in a clear, eloquent, and precise manner.

The study confirms that inhaled NO is able to selectively vasodilate the pulmonary artery circulation without decreasing SAP. As expected, these changes in PVR resulted in a significant substantial decrease in right ventricular work. There are few data on the effects of NO after cardiac operations. Most clinical studies have been done on patients who had pulmonary hypertension or ARDS with different degrees of hypoxic pulmonary vasoconstriction. In these patients, NO improves oxygenation and decreases the hypoxic vasoconstriction. By dilating vessels next to ventilated alveoli, NO distributes blood flow away from nonventilated areas, improving systemic oxygenation. It is unclear from these what direct effect NO has on general indexes of PVR. The patient undergoing cardiac operation, in contrast, offers a unique opportunity to observe the direct effects of NO on pulmonary vasculature. These patients can be safely instrumented, and most of the variables affecting PVR, namely $\mathrm{po}_{2}$, carbon dioxide tension, and $\mathrm{pH}$, can be controlled.

I have three comments and three questions. The first thing that caught my attention when I reviewed the manuscript, with which the authors graciously provided me well in advance, was that NO worked in all patients studied. From personal experience with NO in the pediatric population, I was prepared to accept that NO did not modify PVR in a significant number of patients. Are we in the presence of pulmonary hypertension with a single cause? Do these findings help identify which mechanism is causing pulmonary vasoconstriction after cardiopulmonary bypass?

Dr. Fullerton. To be honest, I do not know the answer to your question. I think that if one looks at how NO works, it requires intact intracellular mechanisms within the vascular smooth muscle. It is our working hypothesis that the vascular smooth muscle as well as the endothelium is injured in certain settings of lung injury. Perhaps in those patients the mechanism within the smooth muscle cells, specifically guanylate cyclase, is unable to respond to the administration of inhaled NO. If guanylate cyclase cannot make cGMP in response to NO, NO is ineffective. We deliberately chose a homogeneous group of patients, those undergoing coronary artery bypass. As we continue to collect data, it is my anecdotal observation that patients who have severe pulmonary hypertension from valvular disease respond much less favorably to inhaled NO. I wonder whether some of the vascular remodeling that goes on with chronic venous congestion in the left atrium, for instance, may affect these mechanisms within the 
smooth muscle cell, rendering such patients less responsive to NO.

Dr. Wernly. If we accept that the increase in PVR is a result of endothelium dysfunction, I wonder whether these findings will stimulate us to explore ways to better protect the endothelium during cardiopulmonary bypass.

My second question deals with lack of changes in LAP. Recent clinical studies in patients with ARDS have demonstrated a modest yet significant decrease in occluded PAP, probably as a result of changes in LAP. In contrast, your patients did not demonstrate any changes in LAP. I wonder whether the fact that the pericardium was opened in all your patients explains the lack of decrease in LAP. As you know, there is a "volume competition" in the intact patient when the right ventricle dilates in response to increases in afterload, which obviously did not take place here. Also, do you think that transesophageal echocardiography could have demonstrated changes in heart chamber dimensions in response to NO?

Dr. Fullerton. We deliberately studied patients in the operating room for just that reason, to minimize the number of confounding variables. I believe that it is an excellent suggestion to use transesophageal echocardiography to help get some other parameter to follow in terms of ventricular function. We have not employed that modality, but it is an excellent idea.

One of the reasons we believe in measuring LAP directly, rather than relying on wedge pressure, is that our data as well as data published by others have shown a dissociation of those two numbers in approximately $25 \%$ of paired measured samples. We therefore do not measure the wedge pressure; rather, for the purposes of studies like this, we have studied LAP directly.

Dr. Wernly. My third question deals with the possibility that NO may depress myocardial contractility. I found it interesting that despite the beneficial effects of NO on right ventricular work, there were no beneficial changes in CO. Do you think that this is because these patients did not have right ventricular dysfunction? Or is it perhaps because the benefits were "canceled" by a subtle negative effect on myocardial contractility?

Dr. Fullerton. I do not think that there is any way to answer that question from our data, but my gut feeling is that NO may well have a negative inotropic effect on the myocardium. I think that if you look at other studies in which pulmonary vasodilators have been administered there is typically an increase in CO as PVR falls. Consistently, however, both in patients with ARDS and now in this study in which NO was administered, $\mathrm{CO}$ has not changed. I therefore think that the reduction in right ventricular afterload may have been counterbalanced by the negative inotropic effect of some circulating element leaving the lungs and entering the myocardium. Unfortunately, our study was not able to address that issue.

Dr. Wernly. I thank the Association for the privilege of discussing this presentation, which I believe is a significant contribution to our understanding of pulmonary circulation.

Dr. Winfield J. Wells (Los Angeles, Calif.). You have hinted that you have data on patients with mitral disease and elevated PAP. Have you done these same studies on that group?

Dr. Fullerton. In a relatively small number of patients, we have not found that NO has been very effective at all. There has been a very small reduction in PAP and a small reduction in PVR. My gut feeling is that it probably has something to do with the inherent differences in this remodeling of the pulmonary circulation, which is of course well understood in mitral stenosis, that prevents those particular vessels from responding to NO.

Dr. Wells. A follow-up is obviously to ask your thoughts about an experimental model that might be able to tell us why this agent is not working in this disease process.

Dr. Fullerton. As you know, we have a couple of different models of acute lung injury ongoing in our laboratory, and our emphasis has been to try to get a better handle on why cGMP may not be generated in response to stimulation by NO. That is what we are working on, and although I do not know whether that will provide any insight into this, I am hopeful.

Dr. Charles M. Rucker (Phoenix, Ariz). I just wanted to follow up. When you mentioned that you think that perhaps there is a decrement in function of cGMP guanylate cyclase in patients with pulmonary hypertension, do you think there is any dysfunction in NO synthase itself. If you do, do you think that it is related to inducible NO or constitutive NO?

Dr. Fullerton. That is a hard question to answer. I have no personal knowledge, but judging from what others have written in the literature, I think that NO synthase is probably intact. In isolated lung preparations in which the perfusate is altered, the metabolites of NO that come out in the effluent appear to be unchanged despite infliction of a variety of forms of lung injury.

\section{Appendix}

Hemodynamic formulas used are as follows:

$$
\begin{gathered}
\operatorname{PVR}\left(\text { dynes } \cdot \mathrm{sec} \cdot \mathrm{cm}^{-5}\right)=\frac{\text { MPAP }-\mathrm{LAP}}{\mathrm{CO}} \times 80 \\
\operatorname{SVR}\left(\text { dynes } \cdot \mathrm{sec} \cdot \mathrm{cm}^{-5}\right)=\frac{\mathrm{MSAP}-\mathrm{CVP}}{\mathrm{CO}} \times 80 \\
\mathrm{CI}=\frac{\mathrm{CO}}{\mathrm{BSA}}
\end{gathered}
$$

$\operatorname{RVSWI}\left(\mathrm{gm} / \mathrm{m}^{2}\right)=\frac{\mathrm{CI}}{\mathrm{HR}} \times \mathrm{MPAP} \times 0.0144$

$$
\text { TPG }(\mathrm{mmHg})=\mathrm{MPAP}-\mathrm{LAP}
$$

where $M S A P$ is mean SAP, $C V P$ is central venous pressure, $C I$ is cardiac index, $B S A$ is body surface area, and $H R$ is heart rate. 